\title{
Contrivances to Assist Forest Machine Operator on Forest Road with Steep Slope
}

\author{
Katsutoshi Saibara $^{a}$, Shigeomi Nishigaki ${ }^{b}$, Fujio Matsuda ${ }^{c}$ and Shinichi Kubota ${ }^{d}$ \\ ${ }^{a}$ Kick, Co., Ltd., , Japan \\ ${ }^{b}$ Mazaran, Co., Ltd., and Kick, Co., Ltd., Japan \\ ${ }^{c}$ Hitachi Construction Machinery Co., Ltd., Japan \\ ${ }^{d}$ Mizobuchi Forestry, Co., Ltd., Japan \\ E-mail: saibara@c2mp.com, sleepingbear@c2mp.com, f.matsuda.kf@hitachi-kenki.com, \\ mizobuchi-ringyo1967@deluxe.ocn.ne.jp
}

\begin{abstract}
-
As for forest harvesting in Japan, machine operators have to handle their own forest machines on forest road with steep slope in the deep mountains. One common hazard that they are always facing is machine stability under different ground conditions. This paper presents the contrivances to provide the people concerned with low-cost Best Management Practices (BMPs), which would be firsthand knowledge of the harvest area being considered, and could support the machine operators who work for harvest operations, and logging road construction and maintenance. First, this paper presents visualizations of terrain attributes. Secondly, are described methods to reduce time and effort on collecting data required by construction, maintenance and restoration of forest road. Thirdly, this paper shows advance alert system pertaining to posture of machine body during the operations, and methods to provide the people concerned in advance with information on the situations of the forest road and the surroundings. Finally, remarks are described.
\end{abstract}

Keywords -

Forest road; Machine stability; Contrivance; BMPs; Open source software; R; Advance alert; Advance proximity warning

\section{Introduction}

A large quantity of man-made forest of Japanese cedars and Japanese cypresses have been planted in the postwar Japan. The harvest operations have been and are executed by small-scale firms of forestry contractors and landowners. Forest managers, machine operators, loggers, self-employed landowners, and other workers have been and are working for the harvest operations.
Forest roads are composed of forest service roads, logging road, skid trails and landings. The forest service road is a type of rudimentary access road. The logging roads are constructed to provide access to the forest for logging and other forest management operations. The logging roads are commonly narrow, winding, and unpaved, but main haul roads can be widened, straightened or paved if traffic volume warrants it [1]. Skid trails are used to get forest products from the woods to a landing. A landing is used to stockpile timber for loading onto logging trucks. Forest service roads connect the landings to existing public roads [2]

Then machine operators have to handle their own forest machines on forest roads with steep slopes in the deep forest mountains. Figure 1 shows the deep forest mountains being analyzed in this study, which lie approximately $15 \mathrm{~km}$ away northeast of Kochi city in Japan.

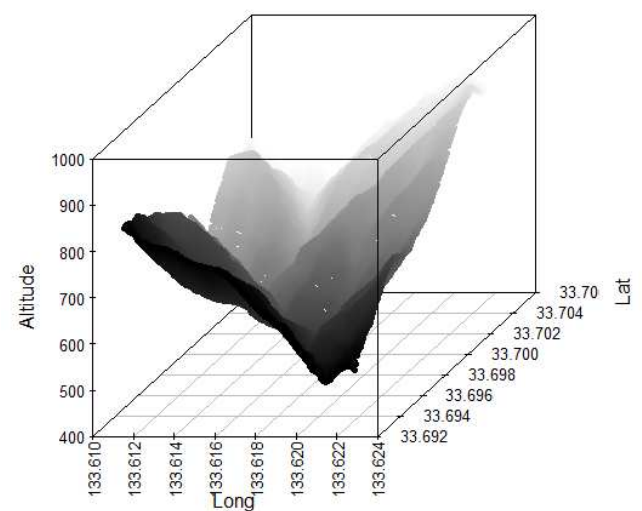

Figure 1. Deep forest mountains being analyzed 
In this study, it aims to develop contrivances to provide them with low-cost Best Management Practices (BMPs), which would be firsthand knowledge of the harvest area being considered and could support them who work for harvest operations. The contrivances would be developed by utilizing open source software based on GNU General Public License [3].

Of particular concern in this study are the contrivances that aim to:

(1) Visualize terrain attributes

(2) Reduce time and effort on collecting data required by construction, maintenance and restoration of forest road,

(3) Provide operators with advance alerts pertaining to machine stability during the operations, and

(4) Provide machine operators, forest managers and landowners in advance with information on the situations of the forest road and the surroundings, where harvest operations would be planned and scheduled.

\section{Terrain Attributes}

The deep forest mountains are outlined and visualized below. The visualizations and the statistics presented here could be done by the R, which is a language and environment for statistical computing and graphics [4]. Besides, the other statics, for example, plan curvature, profile curvature, roughness, etc. could be also computed by the R [5]. For want of space, these statistics are left out in this paper.

Figure 2 shows the ground surface contour of the deep forest mountains and the existing logging road.

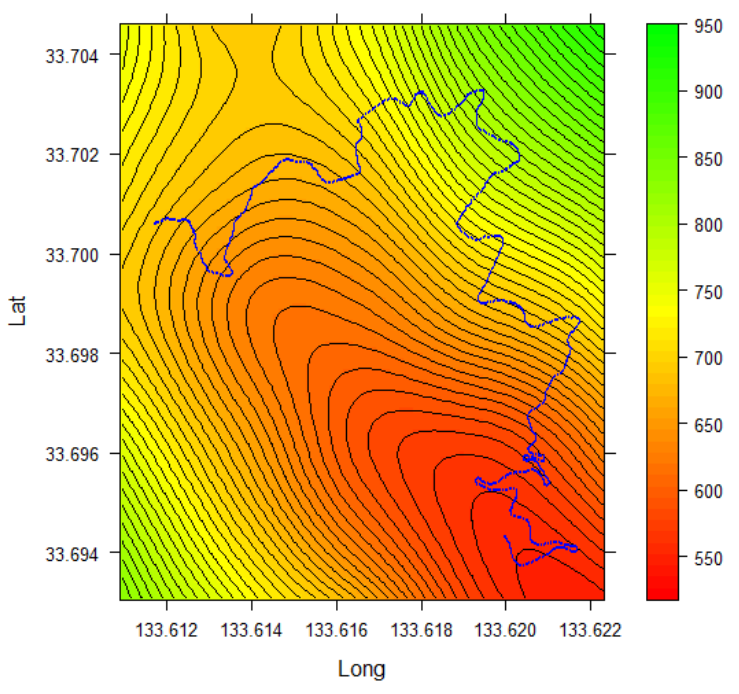

Figure 2. Ground surface contour and existing logging road
Figure 3 shows histograms regarding the statistics of the slope, aspect, TPI, and TRI of the deep forest mountain. The term of TPI is an abbreviation of the Topographic Position Index. The TPI is the basis of the classification system and is simply the difference between a cell elevation value and the average elevation of the neighborhood around that cell. Positive values mean the cell is higher than its surroundings while negative values mean it is lower [6]. TRI (Terrain Ruggedness Index) is the mean of the absolute differences between the value of a cell and the value of its 8 surrounding cells [7].

The slope distribution appears bimodal, two peaks (local maxima), and moderately skewed left. It can be seen from the histogram that all over the mountains has steep slopes more than 10 degree. The aspect distribution is bimodal, that is, easting or westing. The TPI distribution is symmetric and peaky, and has some outliers. The outliers are probably canyons or ridgelines. The TRI distribution is somewhat like bimodal, moderately skewed left, heavy-tailed at left, and has some outliers at right. It shows that some places in the mountains are very rugged.
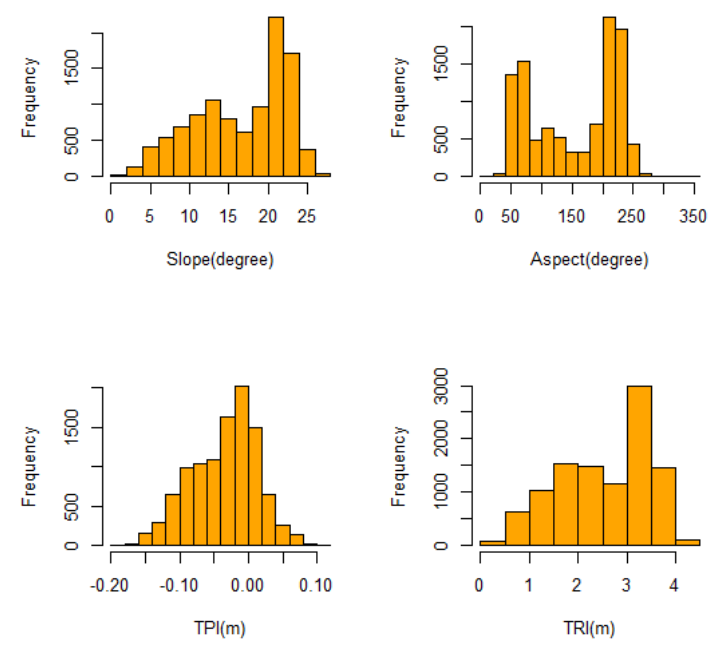

Figure 3. Histograms regarding the statistics

There are two evaluation criteria sets with respect to terrain attributes as shown below.

(1) Criteria set based on TPI and slope [8]:

1) Canyon Bottom: TPI $<-8$,

2) Gentle Slope: $-8<$ TPI $<8$ and Slope $<6^{\circ}$,

3) Steep Slope: $-8<$ TPI $<8$ and $6^{\circ}<$ Slope, and

4) Ridgeline: $8<$ TPI ;

(2) Landslide susceptibility [9]: 
1) Low: slope $\leq 11^{\circ}$,

2) Moderate: $11^{\circ}<$ slope $<16^{\circ}$, and

3) High: $16^{\circ}<$ slope.

Figure 4 shows that there are many spots with steep slopes more than 20 degree. Although logging road should be constructed with avoidance of the spots with these steep slopes as far as possible, the logging road has been helplessly constructed for commercial thinning.

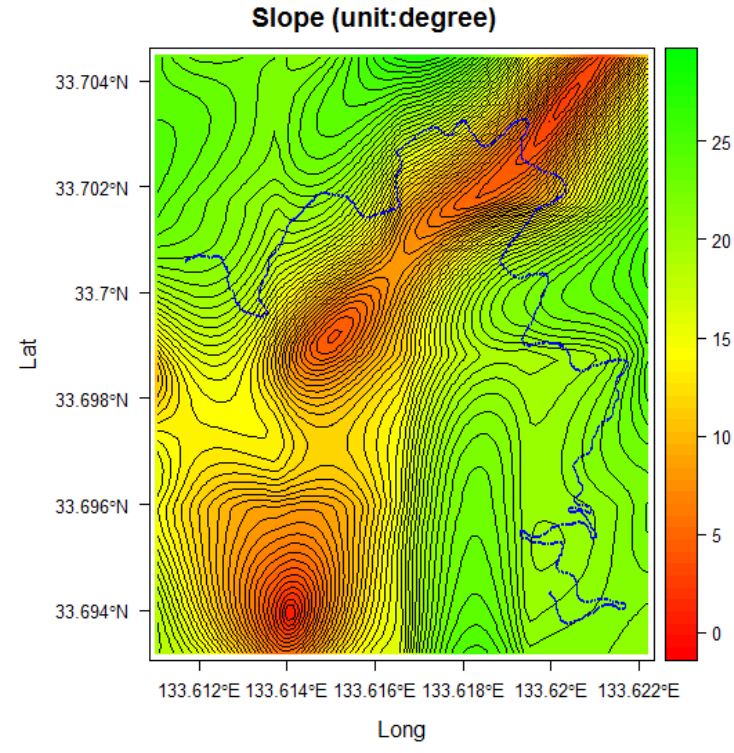

Figure 4. Visualization of slope

It can be said from Figure 3, Figure 4, and the above criteria sets that this terrain has:

(1) Some canyon and ridgeline;

(2) Many spots with steep slopes, and

(3) High landslide risk.

Figure 5 shows the TRI (Terrain Ruggedness Index). Looking Figure 5 at a glance, we can easily see that the existing road runs through the comparatively small difference in elevation of the deep mountains.

The logging road has been constructed for use all year long for harvesting and transport, and has unpaved surfaces of dirt and gravels with ancillary structures, such as:

(1) Skid trails

(2) Landings,

(3) Turntables,

(4) Turnouts

(5) Bridges,

(6) Fords,

(7) Grade breaks,

(8) Ditches,

(9) Culverts,

(10) Cross pipe,

(11) Riprap at ends of pipe or culvert, and

(12) Diversion swales, and forth

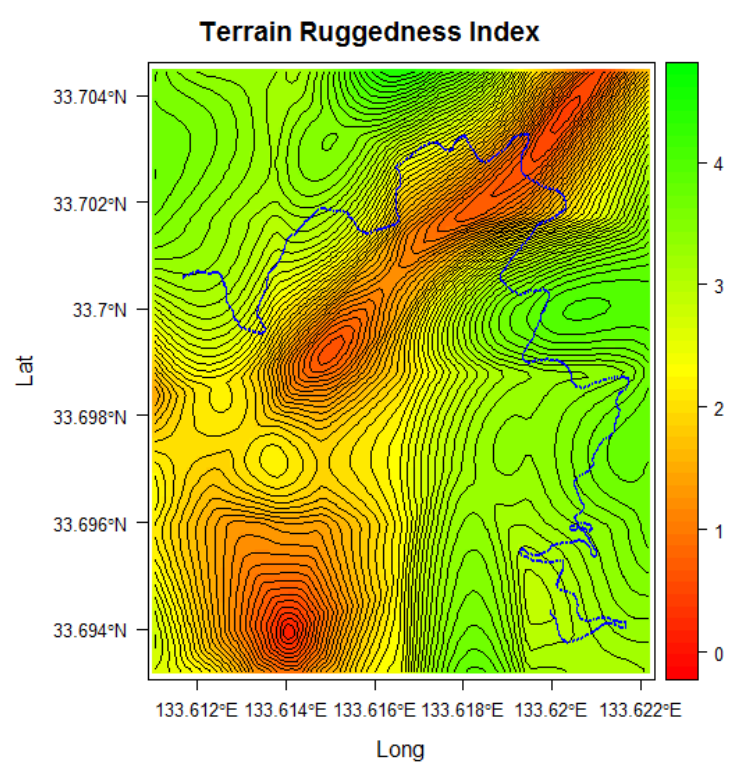

Figure 5. Visualization of TRI

The grade break is a gradual break in grade on a logging road to limit water flow by decreasing the concentration and the velocity. The diversion swale is a vegetated trough that carries or diverts water to reduce the erosion and to avoid washing over the top of the bank.

\section{Reduction of Time and Effort on Collecting Data}

It is time-consuming to gather data in order to identify dangerous spots and excessive inclined spots, and any damage and deterioration of the ancillary structures. The dangerous spots and excessive inclined spots might be latent in logging road, and could cause skidding or rolling over of machine and make operator slip, trips, and fall out of the machine. The damage and deterioration of the ancillary structures could cause falling rocks, landslide, water flood, and so forth. The advance alert system could be applied to reduce time and efforts on collecting data pertaining to dangerous spots latent in and slope of the logging road, and any damage and deterioration of the ancillary structures.

\subsection{Finding Dangerous Spots Latent in Logging Road}

Forest environments in the deep mountains are always changing dynamically. The changes are often unpredictable. Machine operators have to handle their own forest machines based on their own realistic 
sensation given on their seat of pants in such severe environment.

The dangerous spots might be caused by changes in operating conditions such as wash-outs, gulleys, wheel ruts, puddling, frost heaving, soil disturbance, erosion, disruption due to water flood, sediment, and so on. Then the dangerous spots might be latent in the logging roads.

An operator could drive a light motor vehicle with the advance alert system on the logging road. Severe phenomena could be detected by identifying change points based on existing trends of consecutive increasing or decreasing values in time series of tri-axial acceleration responses. Finding seven consecutive increasing or decreasing values is almost the same as the probability to have a car accident in one year in Japan. Then it becomes possible to find severe phenomena related to the dangerous spots of those, for example, front and back skiddy spots, sideway skiddy spots, and severe bumpy spots.

Figure 6 shows the time points of advance alert "caution" that was triggered based on tri-axial acceleration responses obtained by driving a light motor vehicle on the logging roads.
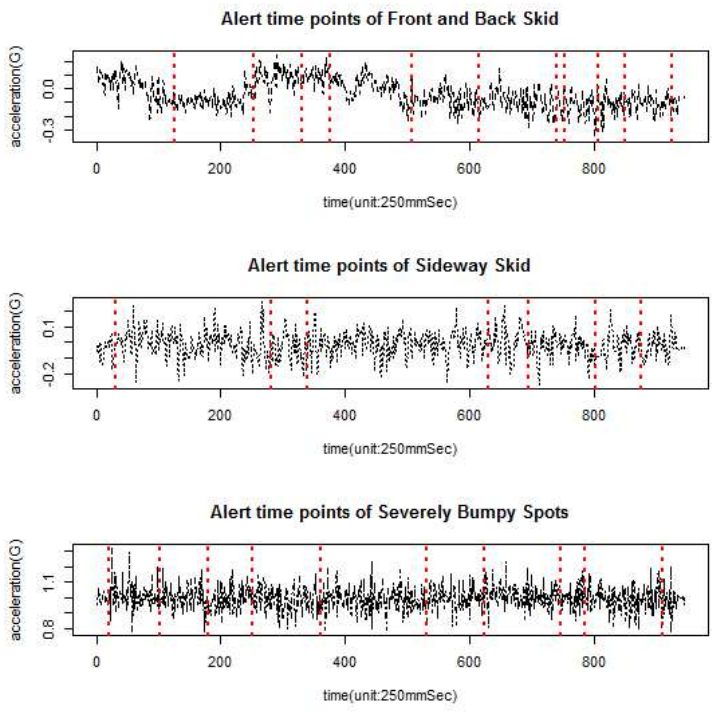

Figure 6. Time points when advanced alert "cautions" being triggered

In order to avoid any accident of skidding or rollover, the advance alert system would give operators advance proximity warning during driving their forest machine when entering into the proximate area of $100 \mathrm{~m}$ range from the dangerous spots like those. The operators could watch the advance proximity warning on the incabin monitor and would slow down the speed.
Front and back skiddy spots, sideway skiddy spots, and severe bumpy spots have almost same position on the logging road. For want of space, the sideway skiddy spots are shown in Figure 7.

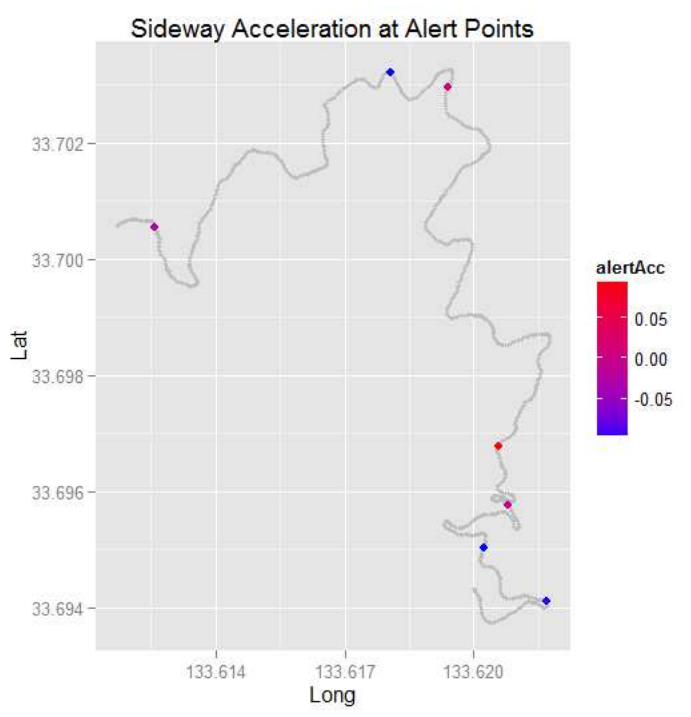

Figure 7. Sideway skiddy spots

\subsection{Measuring Slope of Logging Road}

To do a walk through assessment of work environments, the light motor vehicle with the advance alert system in Figure 8 is repeatedly stopped during one minute and driven $100 \mathrm{~m}$ distance on the logging road.

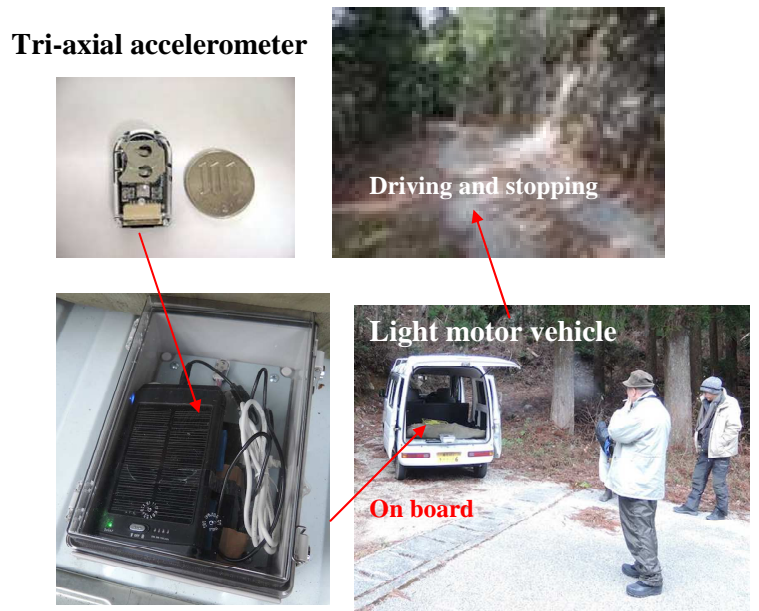

Figure 8. Light motor vehicle with the advance alert system

The advance alert system could calculate and record cross and longitudinal slopes automatically based on the static acceleration of gravity when stopping the light 
motor vehicle. The cross and the longitudinal slopes of the logging road are shown in Figure 9 and Figure 10, respectively.

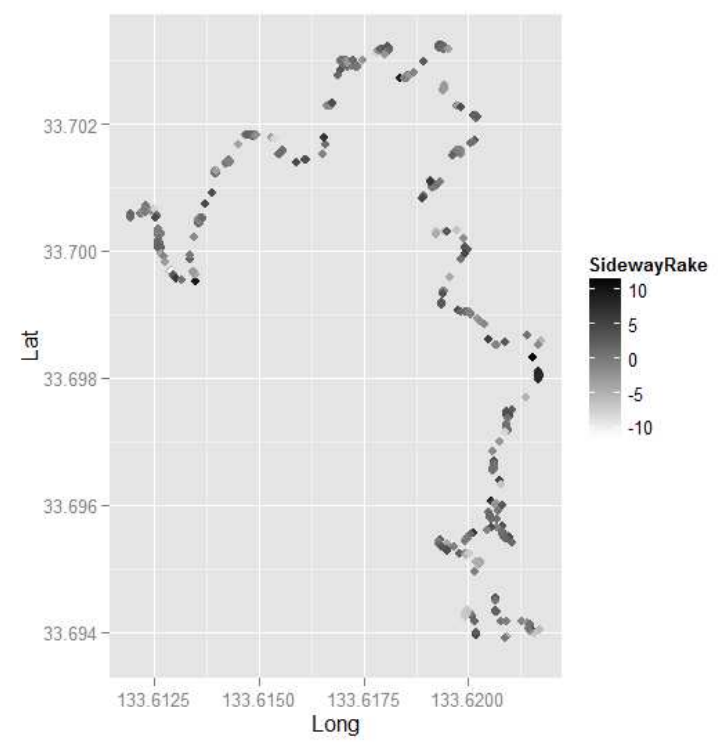

Figure 9. Cross slopes of logging road

It is said to avoid constructing logging road with grades in excess of $10 \%$ [6], [10]. From these Figures, we could easily find dangerous spots with slope in excess of approximately 6 degree, that is, grades of $10 \%$.

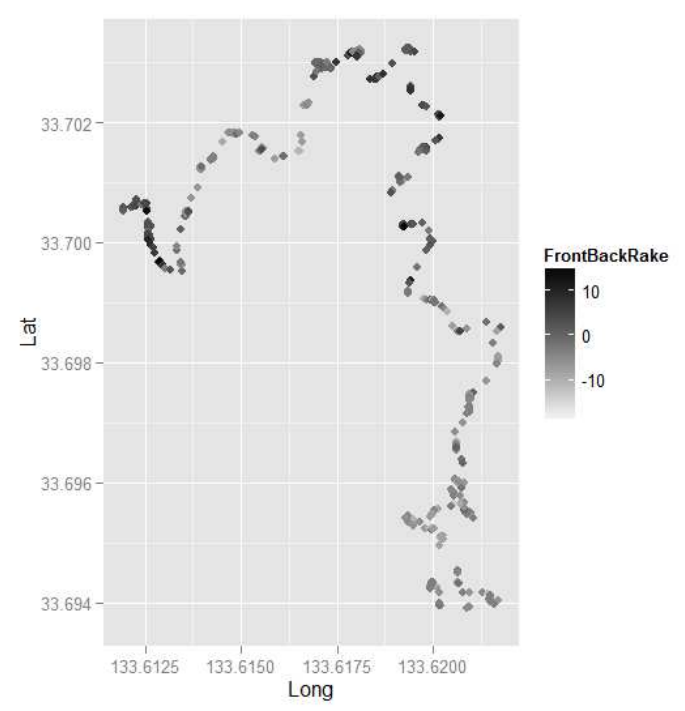

Figure 10. Longitudinal slopes of logging road
Drive Downhill and slash disposal work on the above steep logging road are shown in Figure 11 and Figure 12, respectively.

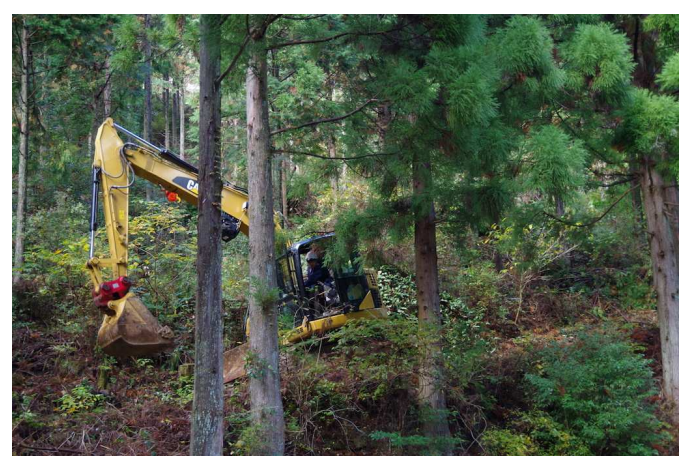

Figure 11. Drive Downhill

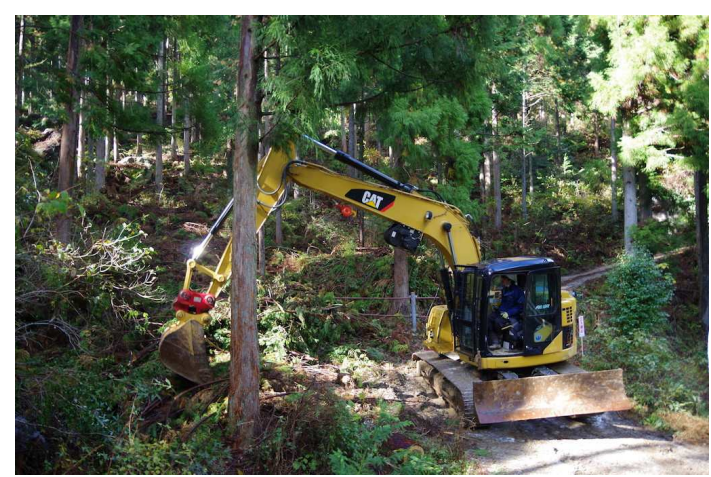

Figure 12. Slash disposal work

In the machine operator's opinion, it becomes hard to operate forest machine at the spot in excess of 12 degree. By the way, logging road should be less than $18 \%$, that is, 10.3 degree in compliance with the logging road construction standard by Kochi prefecture [11].

\subsection{Periodically or Rapidly Mobile Inspections}

Generally, inspection activities are periodically conducted. Then inspection results are documented and pictures are taken as evidence of current conditions or damages or deterioration with a measuring scale or some other reference object. Furthermore, rapid inspection activities would be done for the purpose to determine if further attention to and reconstruction of the ancillary structures are necessary, typically following a typhoon, earthquake, and so on.

When stopping the light motor vehicle, operator will inspect and take pictures of current conditions of the ancillary structures and the surroundings. The each field 
data of those is automatically tagged with time, GPS locations and recorded in digital camera, mobile phone or tablet devices, and also manually uploaded to the database management system.

Automatically or manually, acquiring and recording data as described above could reduce time consumed to gather field data in ordinal situation, and to narrow down and choose certain points to be watched.

Operators could also review previously the field data before their timber-harvest operations. Forest manager could get significant information on planning and activities necessary for the forest harvesting management. Landowners could confirm the current conditions of the logging road and the ancillary structure.

\section{Advance Alert System of Machine Posture}

When operating forest machine at dangerous spots as noted before, it is significant and required to compensate operator's realistic sensation. The advance alert system consists of an on-board tri-axial accelerometer as shown in Figure 13 and an in-cabin monitor system as shown in Figure 14.

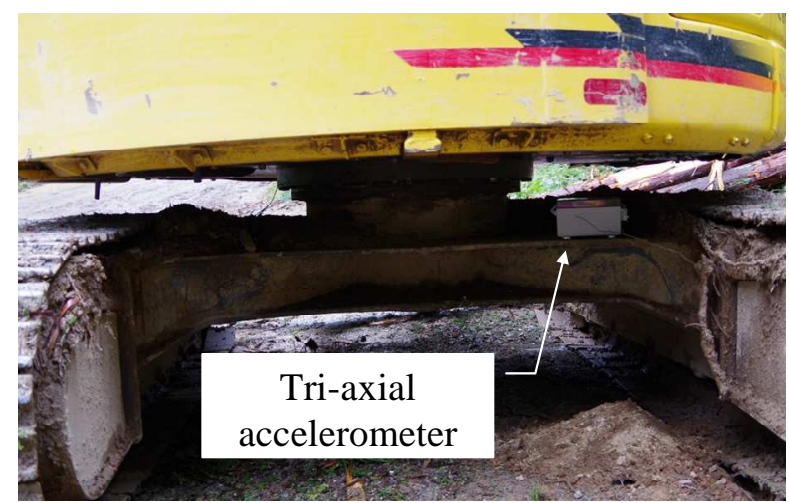

Figure 13. On-board tri-axial accelerometer

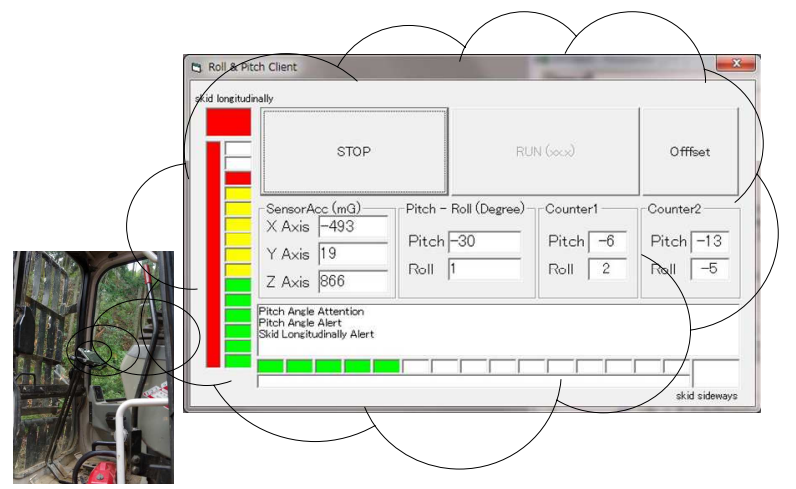

Figure 14. Monitor in the cabin
In this study, it is assumed that acceleration responses measured along cross dimension might represent sideway skid, and ones along longitudinal dimension front-and-back skid. The advance alerts are derived from the existence of trends such as consecutive increasing or decreasing values in time series of acceleration responses, which are sent via wireless communication from on-board tri-axial accelerometer fixed on the carriage body of machine to the in-cabin monitor system.

As mentioned before, seven consecutive increasing or decreasing values equals to the probability to have a traffic accident. Furthermore the thirteen equals to the probability to be killed in a traffic accident in Japan. In the advance alert system, the former is defined as "Caution," the latter "Danger," and otherwise "Safety."

The advance alert system enables the operators to watch advance alert pertaining to sideway and frontand-back skids, and bumping of their own machine. The monitor displays numeric and graphic indicators pertaining to warnings of the colored classes such as:

(1) Green referring to safety,

(2) Yellow referring to caution, and

(3) Red referring to danger.

Operators could watch the advanced alerts in real time, which would compensate their own realistic sensations given on the seat of their pants during operation. Then, the risk latent in harvest activities could be reduced.

\section{Remarks}

People concerned with forest harvesting have to consider far-flung and different coverage problems related to the work plan and operations, the conditions of the work site and the logging roads, the silviculture plan and maintenance, and so forth.

Operators have to examine many different factors in site level decision-making regarding the following matters [10], [11], [12]:

(1) Timber-harvest operations with suitable risk controls as considering location of possible dangerous spots,

(2) Preferred location of log extraction, tracks and log landings,

(3) Machine servicing,

(4) Minimization of impacts on forest resources

(5) Potential water quality,

(6) Seasonal ponds,

(7) Soil productivity,

(8) Work environment information,

(9) Latitude, longitude, and altitude,

(10) Ground surface contours,

(11) Marginal plot of across each coordinates of forest mountains,

(12) Fundamental statistics of slope and aspect, and

(13) Cross and front-and-back slopes. 
Forest manager needs to investigate and deliberate problems in decision- making regarding;

(1) Administration of commercial timber-harvest,

(2) Number, size and design of forest access roads,

(3) Resource allocation,

(4) Maintenance of forest health and productivity, and

(5) Cost effectiveness on harvesting and transportation, and also to work on the best settings for forest harvesting.

Landowners, especially, absentee ones and persons of advanced age, want to know current conditions of their own forest mountain at their own home for:

(1) Commercial thinning, which would be carried out at the right stands at the right time under appropriate stand conditions [13],

(2) Precommercial thinning to enhance woodland productivity,

(3) Redistribution of growth potential to fewer trees past the sapling stage,

(4) Leaving a stand with a desired structure and composition,

(5) Improving the quality of the stand by removing dead, disease and deformed trees, and

(6) Long-term silviculture and harvest plan

Figure 15 shows scheme of contrivances to provide them with low-cost Best Management Practices (BMPs), which would be firsthand knowledge as described above. Since the contrivances are inexpensive and easy-to-use system, its up-front cost might be a less burden to smallscale firms of forest contractors and landowners.

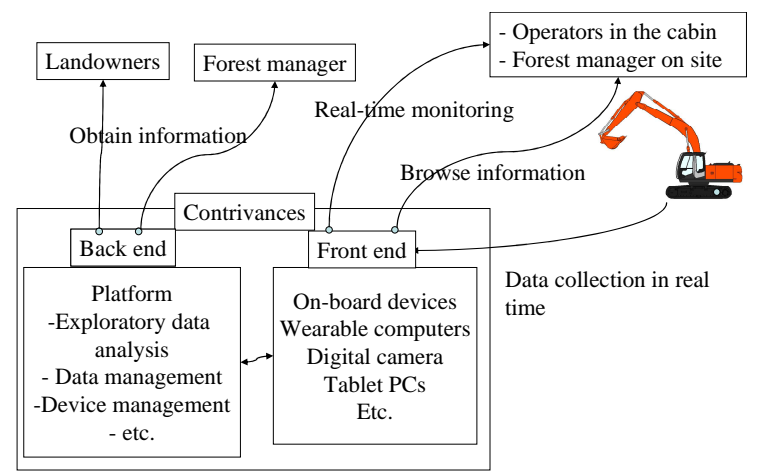

Figure 15. Scheme of contrivance

The contrivances consist of the front-end devices and the back-end platform. The former is on-board devices that function real-time monitoring system for the advance alerts pertaining to dangerous spots and machine stability, and for measurement slope of logging road. The former enable operators to confirm the situations of logging road, the ancillary structures and the surroundings in advance, where the forest harvesting is scheduled. Besides, the operators could watch the advanced alerts in real time, which would compensate their own realistic sensations during their operations. The operators armed in advance with information on the work site could make a suitable plan of harvest operations as considering environmentally sensitive maintenance and restoration. In addition, this device browses work environment information by on-demand processing of requests.

The latter functions exploratory data analysis to generate statistics being required and to visualize them, and manages data gathered and front-end devices, and so on. Machine operators in the cabins and a forest manager on site will be able to import findings on site, which are related to the matters as described before, into this platform from their front-end devices. The people concerned, for example, landowners, forest managers, can obtain information relevant to their harvest operations by accessing the back-end platform.

Consequently, the risk involved in harvest activities would be reduced.

\section{References}

[1] Wikipedia Gravel road. On line: http://en.wikipedia.org/wiki/Gravel_road

[2] State of Wisconsin Department of Natural Resources. CHAPTER 10 Forest Management planning. On line: http://dnr.wi.gov/topic/ForestManagement/guideli nes.html\#toc

[3] Open Source Initiative GNU General Public License. Open line: http://opensource.org/licenses/gpl-2.0.php

[4] The R Project for Statistical Computing. On-line: http://www.r-project.org/

[5] Florinsky, I. V. Accuracy of Local Topographic Variables Derived from Digital Elevation Models. International Journal of Geographical Information Science, 12:1, 47-62, 1998. On line: http://geog.ucsb.edu/ kclarke/G232/terrain/Florins ky_1998.pdf

[6] Jenness J. Topographic Position Index (TPI) v. 1.3a. On line: http://datamirror.csdb.cn/dem/resource/doc/TPI_D ocumentation.pdf

[7] Revolution Analytics: inside-R, terrain \{raster , Terrain characteristics Package: raster Version: 2.2-12. On line: http://www.insider.org/packages/cran/raster/docs/terrain

[8] Dickson, B. and Beier P. 2006. Quantifying the influence of topographic position on cougar (Puma 
concolor) movement In Southern California, USA .

The Zoological Society of London. Journal of

Zoology. doi: 10.1111/j.1469-7998.2006.00215.x.

On line: http://oak.ucc.nau.edu/pb1/vitae/Dickson-

Beier.2007.topog.pdf

[9] Handrich T. E. Landslide Susceptibility in Tryon State Park, Oregon. On line:

http://www.pdx.edu/honors/sites/www.pdx.edu.ho nors/files/Handrich.pdf

[10] State of Wisconsin Department of Natural

Resources. CHAPTER 12 Forest Road

Construction and Maintenance. On line:

http://dnr.wi.gov/topic/ForestManagement/guideli

nes.html\#toc

[11] Kochi prefecture Logging road construction standard (in Japanese), Feb., 2010.

[12] State of Wisconsin Department of Natural Resources. CHAPTER 13 Timber Harvesting. On line:

http://dnr.wi.gov/topic/ForestManagement/guideli nes.html\#toc

[13] Forest Practices Branch, Ministry of Forest, British Columbia. Guideline for Commercial Thinning. On-line:

http://www.for.gov.bc.ca/hfp/publications/00007/c t0726.pdf 